\title{
The effect of intraoral aging of the working stainless steel archwire on the rate of premolar extraction space closure: a randomized clinical trial
}

\author{
Rami A. Al Shayeb ${ }^{1}$ - Elham S. Abu Alhaija ${ }^{2}$ Susan Al-Khateeb ${ }^{1}$ Ayat H. Bani Rashaid ${ }^{3}$
}

Received: 1 March 2021 / Accepted: 7 November 2021 / Published online: 15 November 2021

(c) The Author(s), under exclusive licence to Springer-Verlag GmbH Germany, part of Springer Nature 2021

\begin{abstract}
Objectives The aims of this study were to investigate the effect of the working archwire intra-aging on the rate of upper first premolar space closure and to measure frictional resistance during space closure.

Methods A total of 28 subjects participated in this study. All patients were treated by upper first premolar extraction. Subjects were subdivided into 2 groups: non-replacement side: consisted of the right or left sides of the upper arch where space closure was done using the same $0.019 \times 0.025$-inch SS; replacement side: comprised the other side of the subjects where the working archwire was replaced with a new one each visit. The working archwire in the upper arch was split into 2 halves (new archwire on one side and old one on the other side); each one-half was connected to the other in the midline by a joining shim. Elastomeric chain was used to close extraction spaces. The amount of space closure (mm) was recorded each visit for 3 months.

Results In the non-replacement side, the rate of upper space closure was $0.80 \mathrm{~mm} / \mathrm{month}$ coronally and $0.75 \mathrm{~mm} / \mathrm{month}$ gingivally. In the replacement side, it was $0.69 \mathrm{~mm} / \mathrm{month}$ coronally and $0.67 \mathrm{~mm} / \mathrm{month}$ gingivally $(p>0.05)$. Mean frictional force for the non-replacement side was $3.58 \pm 1.20 \mathrm{~N}$, and it was $2.43 \pm 1.21 \mathrm{~N}$ for the replacement side $(p<0.01)$.

Conclusions Intraoral archwire aging has no effect on the rate of upper premolar space closure/month although frictional resistance of the aged archwire was higher than of the new one.

Clinical relevance

No need to replace $0.019 \times 0.025$-inch SS every visit during space closure to overcome corrosion and frictional resistance.
\end{abstract}

Keywords Aging $\cdot$ Corrosion $\cdot$ Frictional resistance $\cdot$ Space closure

Elham S. Abu Alhaija

elhama@qu.edu.qa

Rami A. Al Shayeb

ra_shayeb@hotmail.com

Susan Al-Khateeb

susank@just.edu.jo

Ayat H. Bani Rashaid

ahbanirashaid@just.edu.jo

1 Division of Orthodontics, Department of Preventive Dentistry, Faculty of Dentistry, Jordan University of Science and Technology, P.O. Box 3030, Irbid, Jordan

2 College of Dental Medicine, Qatar University, P.O. Box 2713, Doha, Qatar

3 Department of Chemistry, Faculty of Science, Jordan University of Science and Technology, P.O. Box 3030, Irbid, Jordan

\section{Introduction}

Sliding mechanics was noted as a highly efficient space closure technique [1] using different space closing methods such as nickel-titanium (NiTi) coil spring and elastomeric chain. However, using this technique, friction is undeniable and is derived from several mechanical factors such as archwire material, bracket material, bracket width, bracket/ archwire angulation, surface roughness of the archwire, and ligature material, and biological factors such as saliva, plaque, acquired pellicle, and corrosion [2].

The components of typical fixed appliance are made mainly of two types of alloys: stainless steel (SS) alloys forming brackets, bands, and archwires; and NiTi alloysmostly archwires. The aggressive environment of the oral cavity can stimulate corrosion of orthodontic alloys. The corrosion process can be enhanced due to several factors 
such as the inherent heterogeneity of metal alloys and their use in combination with other alloys, micro-conversion, the forces acting on the appliances, and the friction between wires and brackets. Metal ions which can be released from SS alloy include cupper $(\mathrm{Cu})$, chromium $(\mathrm{Cr})$, iron $(\mathrm{Fe})$, and nickel $(\mathrm{Ni})$, while nickel $(\mathrm{Ni})$ and titanium $(\mathrm{Ti})$ are released from NiTi alloys [3].

Aging of orthodontic archwire can be manifested as notching, increased surface roughness, and corrosion. Notching can be defined as the mechanical damage to an archwire that occurs during the later stages of binding, which is manifested as defects of varying numbers, patterns, and severity on the surface of an archwire [4]. Kumar et al. [5] evaluated the surface changes of the SS archwires after 6 weeks of intraoral use. They reported that SS archwires showed a significant increase in surface roughness, thus increasing the frictional forces between the archwire-bracket interfaces which would considerably reduce the normal orthodontic forces. The effect of archwire notching on tooth movement is a two-fold effect; first, the presence of notching is evidence of sluggish movement; second, notches create obstacles that interfere with tooth movement [5]. The effect of intraoral aging of the working archwire on the rate of upper premolar space closure using sliding mechanics has not been investigated before. Therefore, the current study was conducted with the following objectives.

\section{Specific objectives or hypotheses}

- To investigate the effect of intraoral aging of the working archwire on the rate of upper first premolar extraction space closure/month.

- To measure frictional resistance of the working SS archwires during space closure using sliding mechanics.

- To report surface changes of the working archwire and bracket (notching) during space closure.

- To compare the above variables between the two study groups.

\section{Materials and methods}

\section{Trial design}

This study was a randomized controlled clinical trial split mouth design with a 1:1 allocation ratio. The methods were not changed after trial initiation.

\section{Participants, eligibility criteria, and settings}

The study was reviewed and approved by the Institutional Review Board at Jordan University of Science and Technology (JUST) and King Abdullah University Hospital (approval number 107/118/2018). This trial was registered at ClinicalTrial.gov with identifier number NCT04549987. The participants for this study were recruited from patients attending orthodontic clinics at the postgraduate dental clinics/JUST. Orthodontic treatment was undertaken at the postgraduate dental teaching clinics/JUST. Study model analysis was performed at the postgraduate dental teaching laboratories/JUST. Frictional testing was done at the faculty of mechanical engineering/JUST and scanning electron microscopy (SEM) was performed at Al al-Bayt University/Jordan .

A total of 28 subjects who fulfilled the inclusion criteria were invited to participate in the study. Age of included subjects averaged $18.92 \pm 2.89$ years. All patients were treated by upper first premolar extraction using fixed appliances. The inclusion and exclusion criteria of the participants in this study are shown in Table 1. Subjects were selected based on these inclusion criteria and were asked to sign a consent form to participate in this study after clarifying the purpose of the intervention.

\section{Sample size}

Sample size was calculated using the $\mathrm{G}^{*}$ power 3.1.9 program. This is according to the power analysis and the assumption of a medium effect size difference of 0.4 between groups based on a split mouth study conducted by Dixon et al. [6] to compare the monthly rate of canine retraction. They reported a mean monthly rate of $0.81 \pm 0.51 \mathrm{~mm}$ and $0.58 \pm 0.30 \mathrm{~mm}$ of canine retraction in NiTi coil spring and powerchain groups, respectively. The power analysis yielded a total sample size estimate of 20 subjects at a conventional alpha level (0.05) and desired power $(1-\beta)$ of 0.80 . Assuming an overall attrition rate of $10 \%$, initial recruitment should target a total of 22 subjects.

Table.1 Inclusion and exclusion criteria of the participants

Age $\geq 16$ years

Proclined upper incisors

Mild upper arch crowding $(<4 \mathrm{~mm})$ or no crowding

Need for upper first premolar extraction

Average lower facial height and maxillomandibular plane angle $\left(22^{\circ}<\mathrm{MM}<32^{\circ}\right)$

Good oral hygiene and healthy periodontium

Exclusion criteria

Poor oral hygiene

Diseases and medications that were likely to affect bone biology

Previous orthodontic treatment

Evidence of bone loss

Active periodontal disease

Smoking

Inclusion criteria 


\section{Randomization}

The intervention was randomly allocated to either the right or left side using the permuted random block size of 2 with 1:1 allocation ratio by one dental research assistant (O.R). The random sequence for the intervention to either right or left sides was concealed in opaque envelopes and shuffled before the intervention to increase the unpredictability of the random allocation sequence. Each patient was asked to pick a sealed envelope to assign the intervention to either the right or left side. Allocation concealment was aimed to prevent selection bias and to protect the assignment sequence until allocation.

\section{Blinding}

The patient was blinded to the intervention used, but it was not possible to blind the clinician during treatment. However, the measurements of the dental casts were performed by the first researcher (R.A) who was blinded to the type of the intervention used/side. Also, the laboratory technician (A.A) who performed the frictional tests was blinded to the intervention used.

\section{Intervention}

\section{Orthodontic intervention}

All patients were treated by the same orthodontic postgraduate student (R.A.) using pre-adjusted edgewise fixed appliance (3 M Gemini Unitek, 0.022-inch MBT prescription brackets) after the extraction of upper first premolars. All teeth were included in the fixed orthodontic appliance including second molars. Teeth alignment started with 0.014-inch nickel-titanium (NiTi) archwire, and then with a sequence of 0.018 -inch, $0.016 \times 0.022$-inch, and $0.019 \times 0.025$-inch NiTi archwires $(3 \mathrm{M}$ Unitek, Monrovia, CA, USA; nitinol superelastic), before $0.019 \times 0.025$ inch stainless steel (SS) rectangular archwire (3 M Unitek Permachrome Resilient Archwire) was reached and kept on patient's mouth for 1 month before space closure. All cases were planned as a minimum anchorage. After reaching $0.019 \times 0.025$-inch SS archwire and according to their random allocation, patients were subdivided into 2 groups:

\section{Group 1: Non-replacement side}

It consisted of the right or left sides of the upper arch (28 patients). In this group, the same $0.019 \times 0.025$-inch SS archwire on the allocated side was kept throughout all the visits during space closure. The premolar extraction space width before treatment (T0) averaged $6.80 \pm 0.24 \mathrm{~mm}$.

\section{Group 2: Replacement side}

It comprised the other side of Group 1 subjects (right or left sides of the upper arch). On this side, the $0.019 \times 0.025$ inch SS archwire was replaced with a new $0.019 \times 0.025$ SS archwire each visit using joining hook. The premolar extraction space width before treatment (T0) averaged $6.85 \pm 0.28 \mathrm{~mm}$.

The $0.019 \times 0.025$-inch SS archwire in the upper arch was split into 2 halves in the midline and each one-half was connected to the other by a wide joining shim (Fig. 1) where the joint was strengthened by adding composite on top. Elastomeric power chain from first molar to first molar was used to close extraction spaces. Patients were instructed to contact the clinic within $24 \mathrm{~h}$ if any bracket was debonded. The patients were followed up monthly where the elastomeric power chain was replaced with a new one. On each monthly visit, alginate impression was taken for the upper arch after removal of the archwire. Dental casts were then produced in the laboratory on the same day, using dental gypsum type II.

\section{Outcomes}

\section{Primary outcome}

The rate of upper first premolar extraction space closure/ month Rate of space closure was calculated as space closure achieved in mm/time ( 3 months). Follow-up models of each subject were labeled and scanned with a Ceramill Map 400 scanner with an accuracy of $0.02 \mathrm{~mm}$ (Amann Girrbach, Koblach, Austria) to obtain a 3-dimensional (3D) model. A Ceramill Mind design software of Amann Girrbach Company was used to measure the extraction space on each model. Two readings were recorded for each side; one coronal reading from the height of contour of adjacent teeth, and one gingival reading from the gingival margin

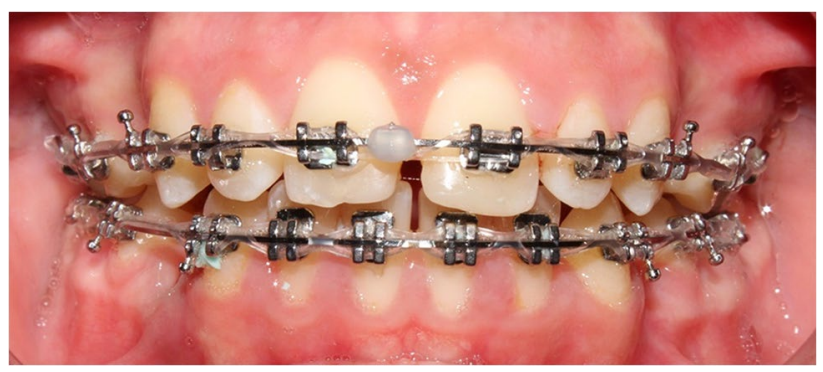

Fig. 1 Two halves of $0.019 \times 0.025$-inch SS archwire connected to each other by a wide joining shim and secured with composite 
of adjacent teeth (distal surface of the canine to the mesial surface of the second premolar). The rate of space closure was measured as $\mathrm{mm} / \mathrm{month}$. The following time points were defined to measure the amount of space closure.

T0: Pre-orthodontic treatment.

T1: When reaching $0.019 \times 0.025$-inch SS archwire and just before space closure.

T2: First follow-up (1 month from T1).

T3: Second follow-up (2 months from T1).

T4: Third follow-up (3 months from T1).

\section{Secondary outcome}

Three-dimensional space analysis-upper arch superimposition Superimposition of the baseline model and the third follow-up model was done using the same software for space closure measurements. Three matching points were identified on each model on the third rugae area to be used for the superimposition process. The labiolingual and mesiodistal movement of the canine and second premolar teeth and the labiolingual movement of the incisor teeth were measured on both sides.

Frictional testing (Figs. 2 and 3 ) The two halves of the upper $0.019 \times 0.25$-inch SS archwire and the brackets used during the study (canines, premolars, and molars) were retrieved from the patients' mouths to perform frictional test. To prevent distortion of the brackets during debonding, a $0.021 \times 0.025$-inch TMA archwire was inserted into brackets and was ligated using elastomeric ligatures and retrieved from the patients' mouths for analysis. The archwire along with the ligated retrieved brackets was transferred and bonded to stone dental models using self-cure acrylic material. After setting of the acrylic and checking the stability of the brackets on the model, the $0.021 \times 0.025$-inch TMA

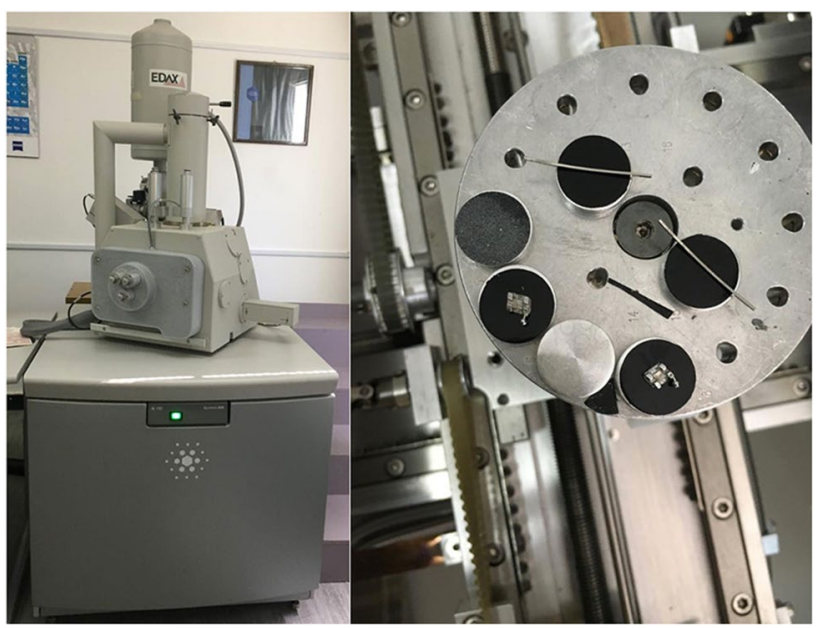

Fig. 3 Specimens fixed to studs and inserted into the chamber

archwire was removed. Then, the corresponding changed or unchanged one-half $0.019 \times 0.25$-inch SS archwire was inserted into the brackets for the frictional test. The archwire on both sides was bent distally into a hook-like configuration and ligated to the brackets using elastomeric ligatures. A special holder for the model was designed at the engineering labs. The holder along with the model was fixed to the base of a universal mechanical testing machine (Fig. 3). The archwire on each side was pulled at a rate of $2 \mathrm{~mm} / \mathrm{min}$ with a load cell fixed to $500 \mathrm{~N}$. Frictional resistance was measured in newton $(\mathrm{N})$ through a computerized program connected to the machine. Multiple readings for frictional force were obtained from the test. Mean frictional force in newton (N) was calculated for every specimen (Fig. 4). The red line represented the increase of frictional force $(Y$-axis) in relation to the distance moved by the archwire ( $X$-axis). When the frictional force was approximately stable, a mean value was calculated for the force over a 3-mm distance.
Fig. 2 The universal mechanical testing machine used in the frictional analysis
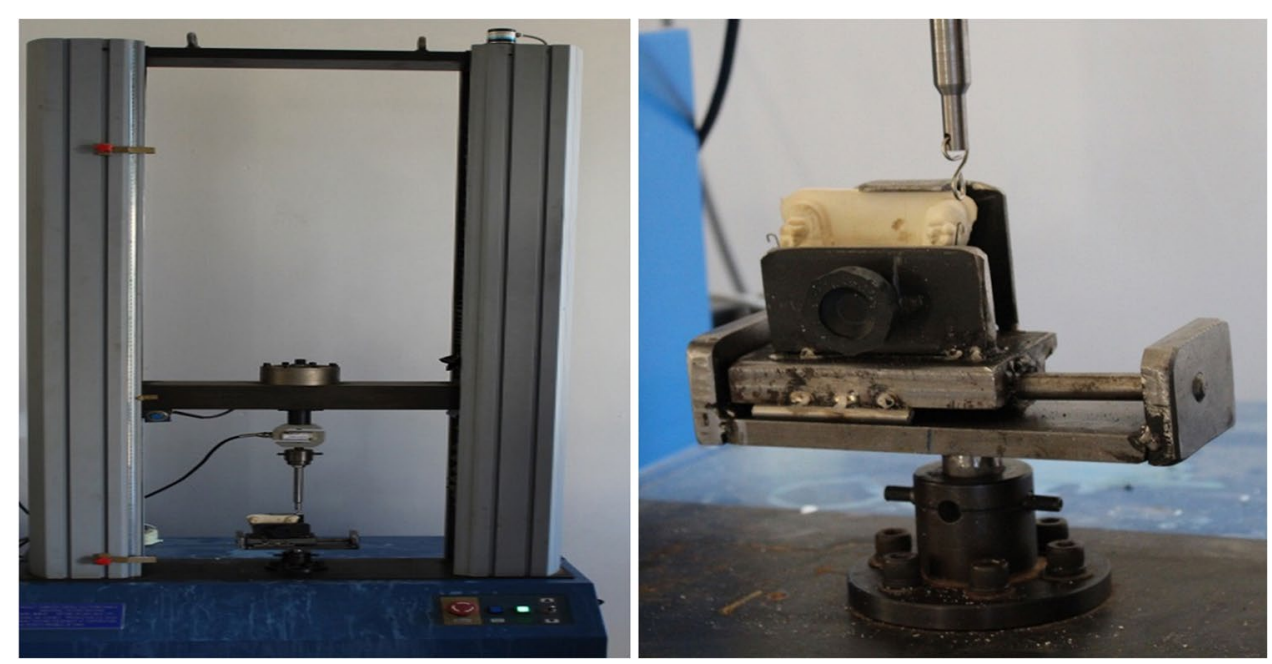
Fig. 4 Frictional force in newton ( $Y$-axis) over 8.5 -mm displacement $(X$-axis) of the tested archwire

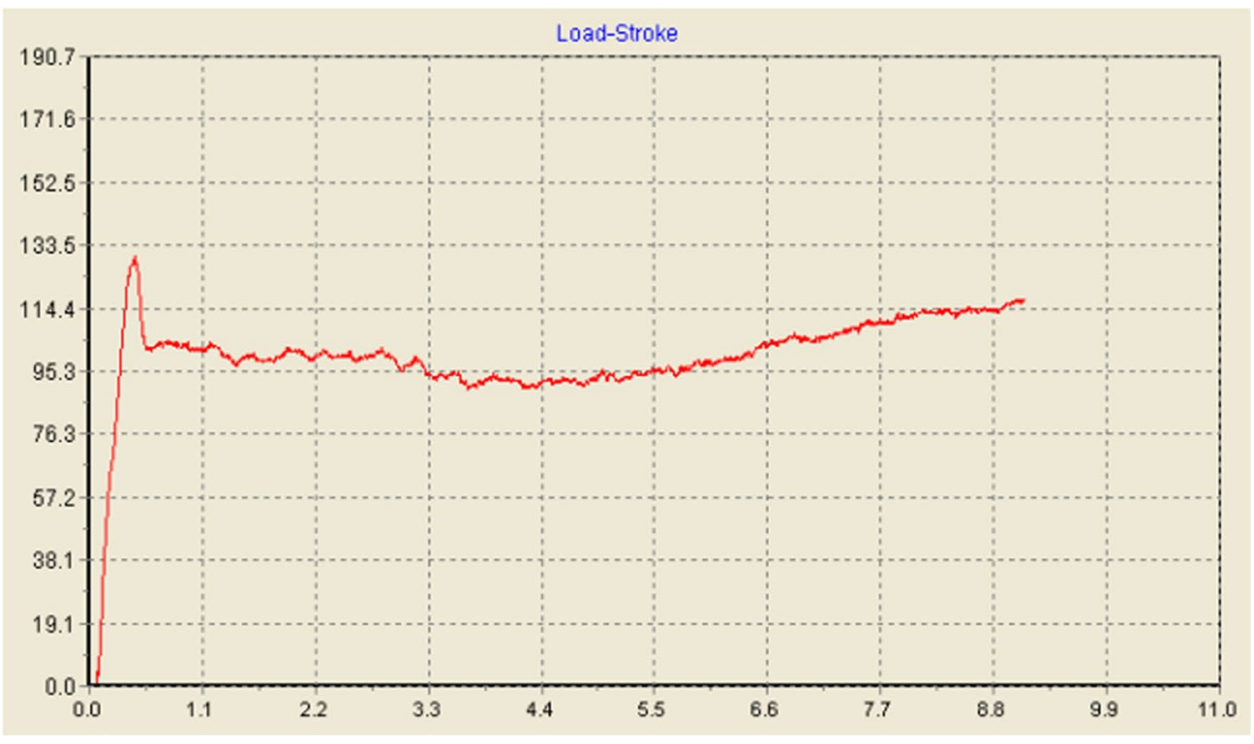

SEM imaging Two brackets (one representing the unchanged archwire group and the other representing the changed archwire group) and two archwire segments (old archwire and new archwire) were viewed under SEM. Every specimen was fixed to a special stud and inserted into an SEM chamber. Images were taken at different magnifications $(50 \times$, $200 \times, 300 \times, 500 \times, 700 \times, 1000 \times$, and $3000 \times)$.

\section{Method error}

Dental casts of 10 randomly selected patients were re-measured after a 2-week interval by the same investigator in the same condition to determine the measurement error in this study. The method error was calculated using Dahlberg's double determination formula [7]. The Dahlberg error was $0.07 \mathrm{~mm}$ for measuring space closure rate.

\section{Interim analyses and stopping guidelines}

Not applicable.

\section{Statistical analysis (primary and secondary outcomes, subgroup analyses)}

Statistical analysis was performed with the use of the Statistical Package for Social Science (SPSS) computer software (SPSS 23, SPSS Inc., IBM, Armonk, NY, USA). Descriptive statistics were calculated for all the measured variables for each group. Differences in the rate and amount of space closure and frictional resistance between the 2 sides were examined using the paired $t$ test. $p$ value was set at 0.05 level.

\section{Results}

\section{Participant flowchart (Fig. 5)}

\section{Subjects}

Subjects were recruited between December 2018 and September 2019, with the final data collection in August 2020. Twenty-eight subjects received the planned intervention.

In the upper arch, in the non-replacement side, 28 patients had their one side extraction space closed using the same $0.019 \times 0.025$-inch SS archwire, while in the replacement side, the same patients had their extraction space (on the other side of the non-replacement side) closed using $0.019 \times 0.025$-inch SS archwire replaced at each followup visit with a new one. During the analysis stage, there were records for 23 patients ( 20 females and 3 males). Five patients were dropped out from the analysis due to failed to show up at their specified appointments due to COVID-19. The endpoint of this study was 3 months after initial space closure to assess the rate of extraction space closure.

\section{Baseline data}

Data regarding age and cephalometric analysis of the subjects in each group are listed in Table 2.

\section{Numbers analyzed for each outcome}

\section{Analyses at each time point}

At T1, 5 patients were excluded from the analysis $(n=23$ per group). Between T2 and T4, none of the subjects was 
Fig. 5 Flow chart showing patients flow during the trial
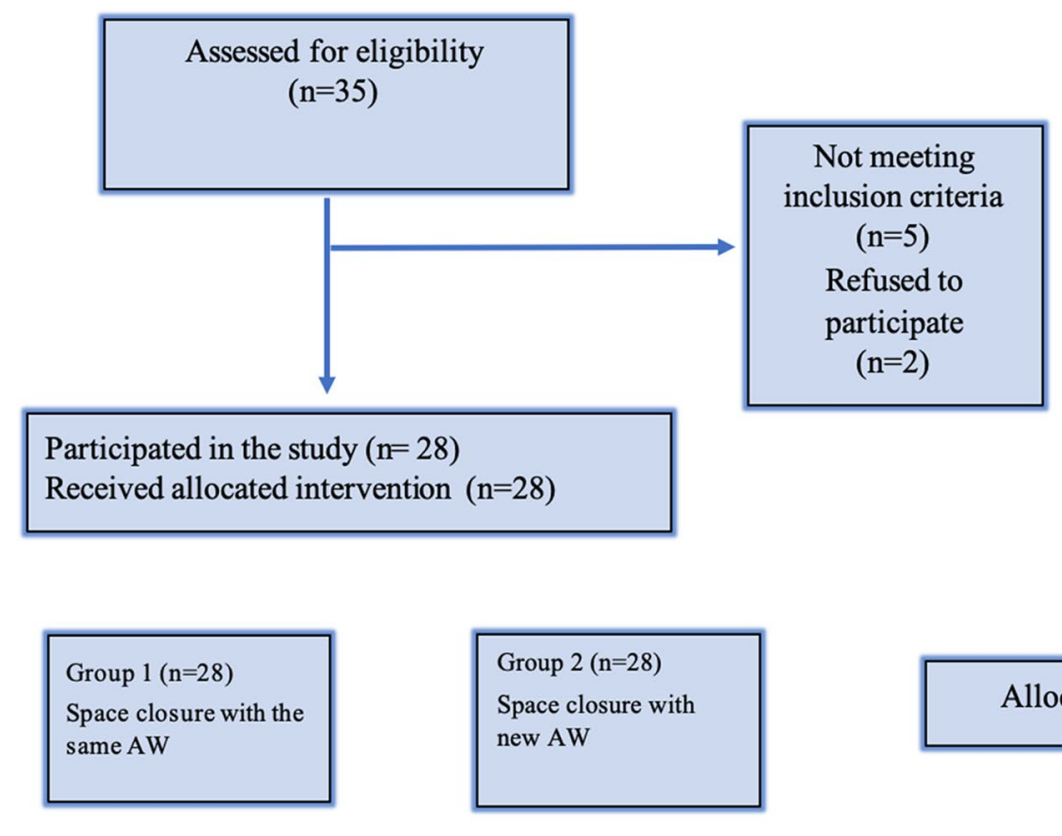

Group $2(\mathrm{n}=28)$

Space closure with new AW
Allocation

Follow-Up
Analyzed ( $\mathrm{n}=23)$
Lost to follow up $(\mathrm{n}=5)$ failed to show up at their specified appointments due to COVID-19
Analyzed $(\mathrm{n}=23)$
Analysis

CONSORT flow chart showing patients flow during the trial

Table.2 Baseline data of the subjects included in the study

\begin{tabular}{lc}
\hline Variable & \multicolumn{1}{c}{ Mean (SD) } \\
\hline SNA & $85(1.31)$ \\
SNB & $79.2(1.52)$ \\
ANB & $4.0(0.56)$ \\
Ui-MxPA & $116.7(1.24)$ \\
Li-MPA & $102.8(1.18)$ \\
MMPA & $27.8(4.21)$ \\
Crowding mm & $4.0(1.13)$ \\
Premolar extraction space mm \\
Group 1 & $6.80(0.24)$ \\
Group 2 & $6.85(0.28)$ \\
\hline
\end{tabular}

excluded from the analysis. During the analysis stage (T1-T4), there was full data for 23 patients (23 quadrant/ group).

\section{Primary outcome}

\section{Rate of upper first premolar extraction space closure}

Means, standard deviations (SDs) of the width of extraction spaces monthly and after 3 months and the rate of space closure/month, and differences between means of the two study groups during the different time intervals are shown in Table 3.

In the non-replacement side, the rate of upper premolar space closure was $0.80 \mathrm{~mm} / \mathrm{month}$ coronally and $0.75 \mathrm{~mm} /$ month gingivally. A total amount of $2.41 \mathrm{~mm}$ coronally and $2.26 \mathrm{~mm}$ gingivally of upper extraction space closure was achieved during 3 months. In the replacement side, the rate of upper premolar space closure was $0.69 \mathrm{~mm} / \mathrm{month}$ coronally and $0.67 \mathrm{~mm} /$ month gingivally. A total amount of $2.07 \mathrm{~mm}$ and $2.02 \mathrm{~mm}$ of upper extraction space closure was achieved during the 3-month period. During the first month of canine retraction, space closure in the non-replacement side was less than that in the replacement side $(p<0.05)$. 
Table.3 Means, SDs of the width of extraction spaces/month and after 3 months and the rate of space closure (coronal and gingival), difference between means, SE, and $T$ values at the different time intervals

\begin{tabular}{|c|c|c|c|c|}
\hline \multirow{2}{*}{\multicolumn{2}{|c|}{$\begin{array}{l}\text { Non-replacement } \\
\text { side } \\
\text { Mean (SD) }\end{array}$}} & Replacement side & $\begin{array}{l}\text { Diff. } \\
\text { between } \\
\text { means (SE) }\end{array}$ & $T$ value \\
\hline & & \multicolumn{3}{|l|}{ Mean (SD) } \\
\hline \multicolumn{5}{|c|}{ Extraction space, coronal } \\
\hline $\mathrm{T} 1$ & $4.59(1.49)$ & $5.07(1.25)$ & $0.48(0.26)$ & $1.89 \mathrm{NS}$ \\
\hline $\mathrm{T} 2$ & $3.65(1.38)$ & $4.11(1.37)$ & $0.45(0.27)$ & $1.66 \mathrm{NS}$ \\
\hline $\mathrm{T} 3$ & $2.78(1.47)$ & $3.34(1.50)$ & $0.57(0.32)$ & $1.75 \mathrm{NS}$ \\
\hline $\mathrm{T} 4$ & $2.25(1.95)$ & $3.00(1.33)$ & $0.75(0.39)$ & $1.44 \mathrm{NS}$ \\
\hline \multicolumn{5}{|c|}{ Extraction space, gingival } \\
\hline $\mathrm{T} 1$ & $4.48(1.55)$ & $4.95(1.26)$ & $0.47(0.22)$ & $2.09 *$ \\
\hline $\mathrm{T} 2$ & $3.61(1.36)$ & $4.04(1.29)$ & $0.44(0.27)$ & $1.62 \mathrm{NS}$ \\
\hline $\mathrm{T} 3$ & $2.73(1.43)$ & $3.27(1.45)$ & $0.54(0.30)$ & $1.79 \mathrm{NS}$ \\
\hline $\mathrm{T} 4$ & $2.27(1.88)$ & $2.91(1.34)$ & $0.64(0.35)$ & $1.08 \mathrm{NS}$ \\
\hline \multicolumn{5}{|c|}{ Total space closure after 3 months, coronally } \\
\hline & $2.41(1.53)$ & $2.07(1.39)$ & $0.34(0.24)$ & $1.44 \mathrm{NS}$ \\
\hline \multicolumn{5}{|c|}{ Total space closure after 3 months, gingivally } \\
\hline & $2.26(1.53)$ & $2.02(1.31)$ & $0.25(0.23)$ & $1.08 \mathrm{NS}$ \\
\hline \multicolumn{5}{|c|}{ Rate of Space closure, coronally } \\
\hline & $0.80(0.51)$ & $0.69(0.46)$ & $0.11(0.08)$ & $1.93 \mathrm{NS}$ \\
\hline \multicolumn{5}{|c|}{ Rate of Space closure, gingivally } \\
\hline & $0.75(0.51)$ & $0.67(0.44)$ & $0.08(0.08)$ & $1.82 \mathrm{NS}$ \\
\hline
\end{tabular}

$T 1$ at the beginning of space closure, T2 1 month, T3 2 months, T4 3 months after initial space closure, $N S$ not significant $*<0.05$

However, after the first month of canine retraction, the differences between the means of the two groups were not statistical $(p>0.05)$.

Means, SDs of amount of teeth movement during extraction space closure (T1-T4) in the upper arch in the 2 studied groups, difference between means, $\mathrm{SE}$, and $p$ value are shown in Table 4.

Upper canines and second premolars moved distally and palatally. The difference between the 2 sides was not significant $(p>0.05)$.

\section{Frictional testing}

Means, SDs of frictional resistance, difference between means, $\mathrm{SE}$, and $p$ value are shown in Table 5.

Mean frictional force of the archwire in the non-replacement side was $3.58 \pm 1.20 \mathrm{~N}$ compared to $2.43 \pm 1.21 \mathrm{~N}$ for the archwire in the replacement side. The difference of $1.15 \mathrm{~N}$ between the means for the two groups was significant at $p<0.01$.

\section{SEM imaging (Figs. 6 and 7)}

Similar surface irregularities were detected on the slots of the two imaged brackets. These included scratches, pits, grooves, and areas of mechanical wear. Images of the nonreplacement side archwire segment showed scratches, pits, grooves, corroded areas, and notches. These features were not detected on the replacement side archwire images.

Harms No negative outcomes were reported by any patients during the trial.

\section{Discussion}

While efficient space closure using sliding mechanics is a desirable goal in any orthodontic treatment, friction is encountered during this type of tooth movement. The focus of this study was to detect any association between space closures with the physical changes that might occur

Table.5 Means, SDs of frictional resistance, difference between the mean, $\mathrm{SE}$, and $p$ values for both study groups

\begin{tabular}{lllll}
\hline & $\begin{array}{l}\text { Non-replace- } \\
\text { ment side }\end{array}$ & $\begin{array}{l}\text { Replacement } \\
\text { side }\end{array}$ & $\begin{array}{l}\text { Diff. } \\
\text { between } \\
\text { means (SE) }\end{array}$ & $p$ value \\
& Mean (SD) & Mean (SD) & & \\
\hline $\begin{array}{l}\text { Frictional } \\
\text { resistance } \\
(\mathrm{N})\end{array}$ & $3.58(1.20)$ & $2.43(1.21)$ & $1.15(0.41)$ & $0.009^{* *}$ \\
\hline
\end{tabular}

${ }^{* * *}$ Significant at $p<0.01$
Table.4 Means, SDs of upper teeth movement during space closure, difference between the means, SE of the mean differences, and $p$ values in both study groups as superimposed on the third rugae area

\begin{tabular}{lllll}
\hline & Non-replacement side & Replacement side & $\begin{array}{l}\text { Diff. between } \\
\text { means (SE) }\end{array}$ & $p$ value \\
& Mean (SD) & Mean (SD) & & \\
\hline Upper 5 palatal movement & $0.36(0.45)$ & $0.35(0.40)$ & $0.004(0.12)$ & $0.973 \mathrm{NS}$ \\
Upper 5 mesial movement & $1.65(1.18)$ & $1.73(1.09)$ & $0.08(0.33)$ & $0.808 \mathrm{NS}$ \\
Upper canine palatal movement & $0.40(0.51)$ & $0.48(0.45)$ & $0.08(0.14)$ & $0.545 \mathrm{NS}$ \\
Upper canine distal movement & $0.60(0.46)$ & $0.60(0.64)$ & $0.008(0.16)$ & $0.963 \mathrm{NS}$ \\
Upper incisors palatal movement & $1.83(0.87)$ & $1.83(0.87)$ & $0.004(0.25)$ & $0.988 \mathrm{NS}$ \\
\hline
\end{tabular}



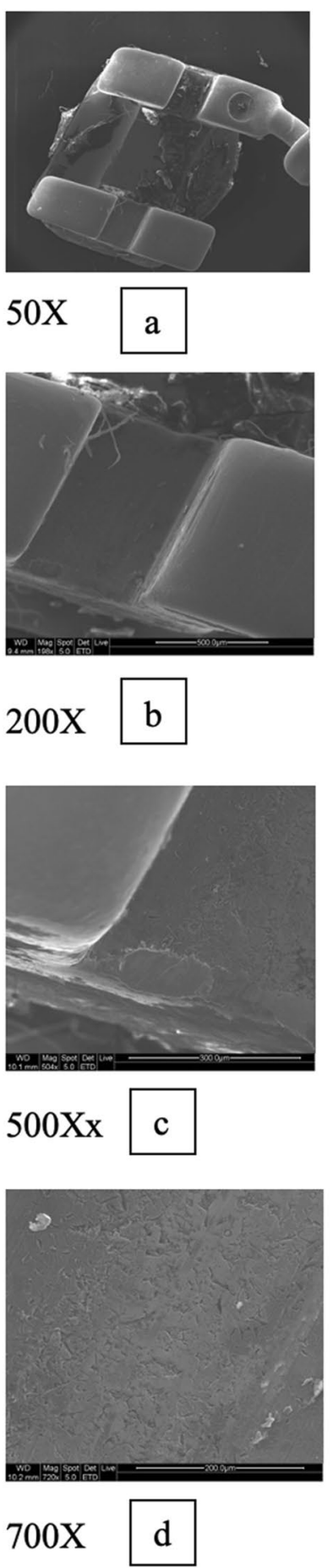
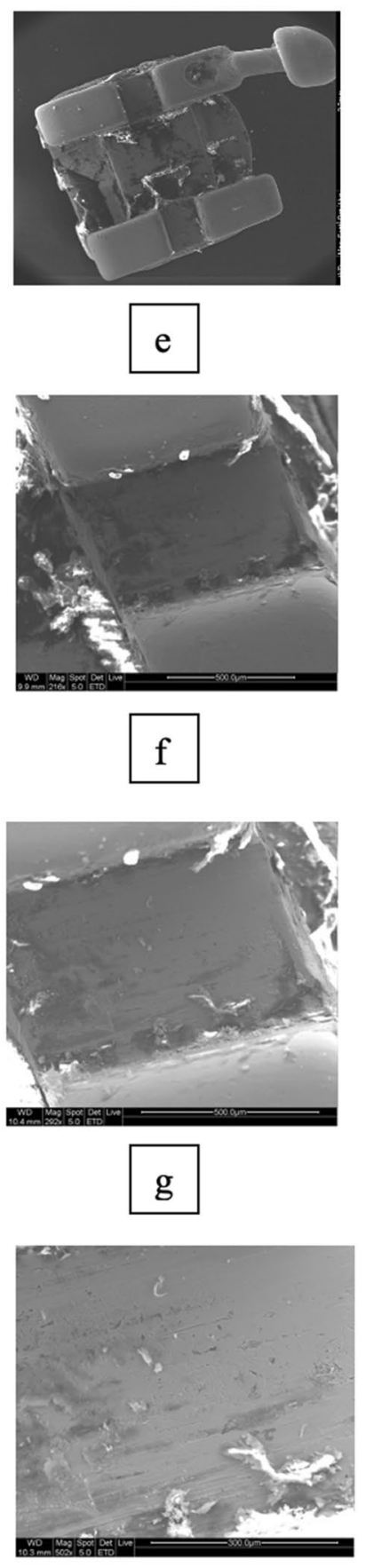

$\mathrm{h}$

Fig. 6 SEM images of brackets of changed archwire group (a-d) and unchanged archwire group (e-h)

on the working archwire, namely surface scratches and notching and corrosion. Most of the previously published papers focused on either the type of force delivery system $[6,8]$, the type of bracket system used [8], or the magnitude of the delivered force [10]. This is the first study
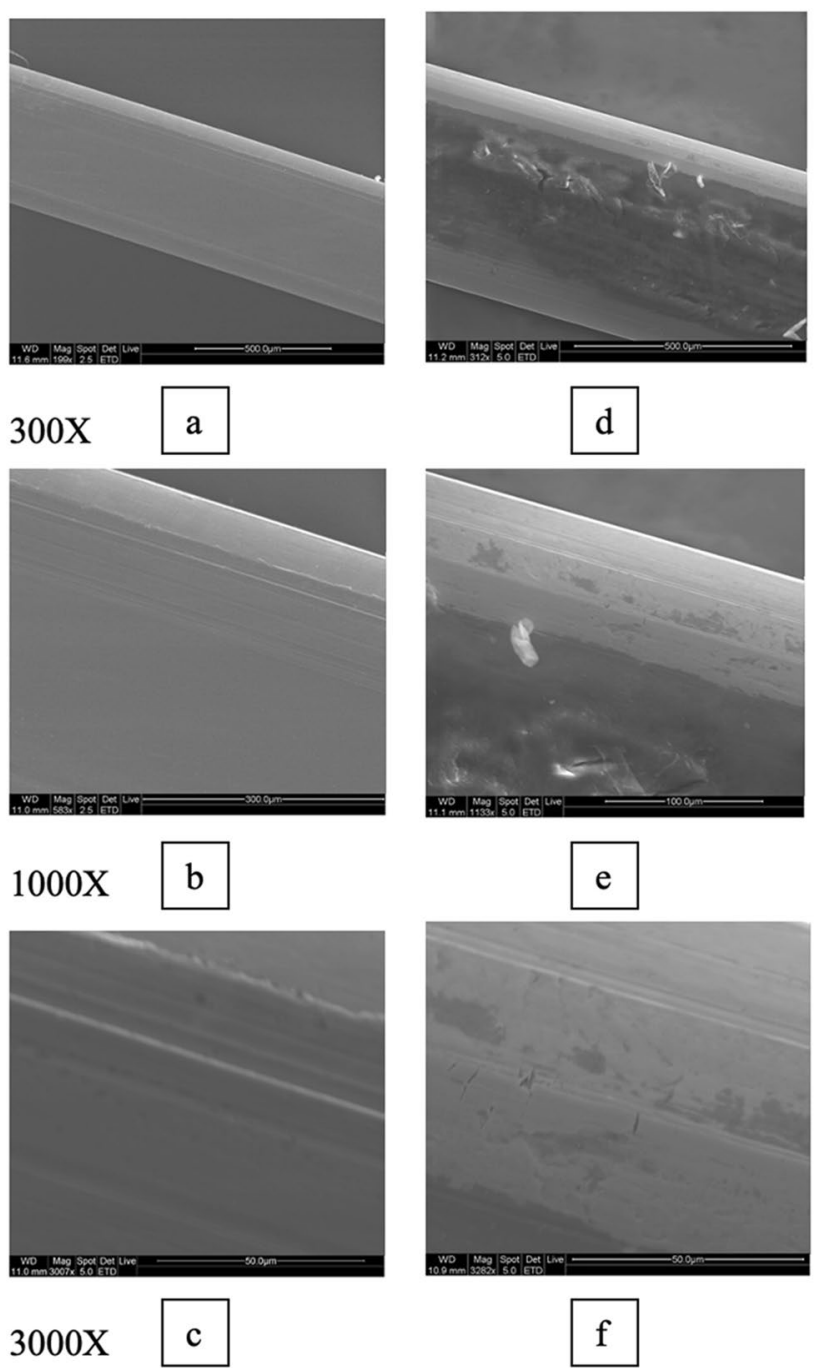

Fig.7 SEM images of changed archwire segment (a-c) and unchanged archwire segment (d-f)

to investigate the effect of intraoral aging of the working archwire on the amount of space closure/month.

A split mouth design was adopted in this study to reduce the biological variability between the subjects [11].

In this study, extraction space was measured coronally and gingivally. Reference points were set at the most prominent points on the distal surface of the canine and the mesial surface of the premolar to obtain a coronal reading. Another two points were set near the proximal gingival margin to obtain a gingival measurement. In his study, Miles [9] measured tooth movement during space closure using the mesial surface of the mesial wing of the premolar bracket and the distal surface of the distal wing of the canine bracket as reference points. These points might be inaccurate due to variations in bracket placement during bonding procedure. On the other hand, Dixon et al. [6] and Nightingale and Jones [12] used the cusp tip of the canine and the buccal groove of 
the first permanent molar as reference points for this measurement which ignored the amount of the space closed by tipping of teeth.

In the current study, space closure was carried out on a rigid rectangular SS archwire to achieve maximum amount of bodily movement [13]. This was evident in the results of this study as there was no significant difference between coronal and gingival readings obtained during the analysis indicating that mainly bodily tooth movement had occurred with very minimal tipping.

The amount of space closure during the first month of canine retraction was less in the non-replacement side. However, the difference in the rate of space closure between the non-replacement and the replacement archwire sides was clinically insignificant after 3 months. This finding indicates that the physical changes that may be associated with archwire aging as evidenced from SEM images did not affect the rate of teeth movement during the 3 months of space closure. Accordingly, changing the archwire at every follow-up visit may be an unnecessary procedure if the aim of changing the wire is to get a more efficient space closure. This was also supported by the three-dimensional analysis done in this study which yielded no significant difference in the movement of canine, premolar, and incisor teeth between the two groups. The reduced tooth movement during the first month of canine retraction in the non-replacement side may be related to frictional forces [14]. Marques et al. [14] found that friction is correlated with the degree of debris and roughness on the archwire surface.

In the current study, a significant difference in frictional resistance between the non-replacement and the replacement sides was noted. This was in agreement with Marques et al. [14] who evaluated the effect of SS archwires aging on frictional resistance and found a significant increase in frictional force with an average increase of $21 \%$ in friction level. Also, Kumar et al. [5] studied the effect of intraoral aging of SS archwires retrieved after 6 weeks of intraoral use on frictional forces. They concluded that aged SS archwires showed increased frictional forces between the archwirebracket interfaces which would reduce the normal orthodontic forces. However, this difference did not have any impact on the rate of tooth movement. In the current study, frictional resistance was measured ex vivo where the archwires were pulled through the brackets in a straight-line traction where this is not the situation in clinical practice. Clinically, orthodontic space closure was carried out using a powerchain applied far from the center of resistance where space closure was achieved through a succession of tipping and uprighting of teeth. The performed ex vivo straight-line traction might not simulate the clinical situation which may explain the lack of correlation between frictional forces and rate of space closure. In addition, other factors may affect frictional forces clinically and were not reproduced experimentally such as surface chemistry, contact area, contact angle between the bracket and the archwire, and binding [14].

The result of this study demonstrates no need to replace $0.019 \times 0.025$-inch SS every visit during space closure to overcome corrosion and frictional resistance.

Limitations of the current study include the following: high female to male ratio; canine retraction was not carried out individually; instead, all anterior teeth were retracted together which may have affected the amount of teeth movement and resulted in crossover effect; the use of elastomeric powerchain with quicker force degradation compared to NiTi coil spring which produces light continuous force. In addition, ex vivo frictional resistance test was carried out which might not simulate the clinical situation.

\section{Conclusions}

Intraoral archwire aging has no effect on the rate of upper premolar space closure/month although frictional resistance of the aged archwire was higher than the new one.

\section{Generalizability}

No need to replace $0.019 \times 0.025$-inch SS every visit during space closure to overcome corrosion and frictional resistance.

Acknowledgements We would like to thank Dr. Obada Rawaga, Dr. Mohammed Humam, Saba Daher, and Hasan Daher for their assistance during the conduction of this study.

Funding The study was supported by the Deanship of Research at Jordan University of Science and Technology (research grant number $53 / 2019)$.

\section{Declarations}

Ethics approval The study was approved by the institutional ethics and research committee at Jordan University of Science and Technology, and it is registered with clinicaltrials.gov registration number NCT04549987.

Consent to participate A written informed consent was obtained from all participants before the treatment.

Conflict of interest The authors declare no competing interests.

\section{References}

1. McLaughlin R, Bennett J (2015) Evolution of treatment mechanics and contemporary appliance design in orthodontics: a 40-year perspective. Am J Orthod Dentofacial Orthop 147:654-662 
2. Barlow M, Kula K (2008) Factors influencing efficiency of sliding mechanics to close extraction space: a systematic review. Orthod Craniofac Res 11:65-73. https://doi.org/10.1111/j.1601-6343

3. Castro SM, Ponces MJ, Lopes JD, Vasconcelos M, Pollmann MCF (2015) Orthodontic wires and its corrosion - the specific case of stainless steel and beta-titanium. J Dent Sci 10:1-7

4. Articolo LC, Kusy K, Saunders CR, Kusy RP (2000) Influence of ceramic and stainless-steel brackets on the notching of archwires during clinical treatment. Euro J Orthod 22:409-425

5. Kumar A, Khanam A, Ghafoor H (2016) Effects of intraoral aging of arch-wires on frictional forces: an ex-vivo study. J Orthod Sci 5:109-116

6. Dixon V, Read MJF, O'Brien KD, Worthington HV, Mandall NA (2002) A randomized clinical trial to compare three methods of orthodontic space closure. J Orthod 29:31-36

7. Dahlberg G (1940) Standard error and medicine. Hum Hered 1(4):313-321

8. Samuels RH, Rudge SJ, Mair LH (1998) A clinical study of space closure with nickel-titanium closed coil springs and an elastic module. Am J Orthod Dentofacial Orthop 114:73-79

9. Miles P (2007) Self-ligating vs conventional twin brackets during en-masse space closure with sliding mechanics. Am J Orthod Dentofacial Orthop 132:223-225
10. Yee JA, Türk T, Elekdağ-Türk S, Cheng LL, Darendeliler MA (2009) Rate of tooth movement under heavy and light continuous orthodontic forces. Am J Orthod Dentofacial Orthop 136:150. e1-9

11. Pandis N, Walsh T, Polychronopoulou A, Katsaros C, Eliades T (2013) Split-mouth designs in orthodontics: an overview with applications to orthodontic clinical trials. Euro J Orthod 35:783-789

12. Nightingale C, Jones SP (2003) A clinical investigation of force delivery systems for orthodontic space closure. J Orthod 30:229-236

13. Tanne K, Koenig HA, Burstone CJ (1988) Moment to force ratios and the center of rotation. Am J Orthod Dentofacial Orthop 94:426-431

14. Marquesa I, Joa A, Gurgel J, Normando D (2010) Debris, roughness and friction of stainless steel archwires following clinical use. Angle Orthod 80:521-527

Publisher's Note Springer Nature remains neutral with regard to jurisdictional claims in published maps and institutional affiliations. 